\title{
Mulheres Intelectuais na IDADe Média: Hildegarda DE Bingen - Entre a Medicina, a Filosofia e a Mística
}

\author{
Marcos Roberto Nunes Costal
}

RESUMO: É corrente se afirmar que antes da Modernidade não há registro de mulheres na construção do pensamento erudito. Que, se tomarmos, por exemplo, a Filosofia e a Teologia, que foram as duas áreas do conhecimento que mais produziram intelectuais, durante a Idade Média, não encontraremos aí a presença de mulheres. Entretanto, apesar de todas as evidências, se vasculharmos a construção do Pensamento Ocidental, veremos que é possível identificar a presença de algumas mulheres já nos tempos remotos, na Antiguidade Clássica e na Patrística (ou Alta Idade Média). Mas é na Escolástica (Baixa Idade Média) que encontramos as primeiras Pensadoras, responsáveis por um sistema autônomo, distinguindo-se como fecundas escritoras, donas de obras tão profundas e importantes quanto as produzidas pelos homens de seu tempo, com os quais muitas vezes dialogaram em pé de igualdade. Dentro desse maravilhoso universo feminino de intelectuais, destacamos, na Escolástica, a figura de Hildegarda de Bingen (1098-1165), da qual trataremos um pouco neste artigo.

PALAVRAS-CHAVE: Medicina. Filosofia. Mística. Idade Média. Mulheres Intelectuais.

\section{VIDA E OBRAS}

Segundo Joseph-Ignasi Saranyana, Hildegarda de Bingen (em alemão Hidelgard von Bingen), última filha do casal de nobres Hildebert e Mechtild, nasceu em 1098, em Bermersheim - sede dos baróes de Sponheim - próximo de Alzey, na Francônia-Renânia, região do Rio Reno (Cf. SARANYANA, 1999 , p. 153, nota 41). Com oito anos de idade, Hildegarda foi confiada à abadessa e ex-condessa Jutta (Judite), filha do Conde Stephen de Sponheim, no mosteiro das beneditinas de Disibodenberg, que foi sua tutora, preceptora ou mestra (magistra).

\footnotetext{
${ }^{1}$ Professor/coordenador da Graduação em Filosofia da UFPE. Professor do Programa de Pós-Graduação (Mestrado e Doutorado) em Filosofia da UFPE/UFPB/UFRN. E-mail: marcosnunescosta@hotmail. com
} 
Além de Jutta (Judite), consta que na instrução de Hildegarda interveio também o monge Volmar, seu primeiro confessor-copista, os quais iniciaram sua educação que, como era costume da época, começava pelo estudo das Escrituras Sagradas, nomeadamente pelos Salmos, a ponto de se dizer que naquele tempo "aprender a ler é aprender a salmejar".

Aos quinze anos de idade, Hildegarda fez votos religiosos, tornandose monja beneditina, passando a viver (em companhia de Jutta) em regime de ascetismo, reclusa em uma pequena cela, usando um cilício de ferro. Em 1136, com a morte de Jutta, Hildegard tornou-se abadessa do mosteiro das beneditinas de Disibodenberg.

Cinco anos depois, aos quarenta e três anos de idade, Hildegarda teve sua primeira grande experiência mística (que foi seguida de outras, das quais resultaram várias obras, conforme veremos mais adiante) ${ }^{2}$, momento em que recebeu - como ressalta ela - "o encargo de Deus" para escrever e pregar, o que implicaria uma mudança radical de vida, ou seja, sair da vida de reclusão e iniciar uma vida de peregrinação/pregação. Por isso, esperou a autorização da Igreja para começar tal tarefa. Primeiro, em carta, recorreu a São Bernardo de Claraval, que a encorajou. Mas, como esta continuou em dúvida, o caso foi levado ao Papa Eugênio III, que, em 1147, durante o Sínodo de Trier, encarregou uma comissão de teólogos, dentre os quais Albero de Couní, bispo de Verdún, para examinar os relatos de suas visóes e, depois de um parecer favorável, autorizou que ela escrevesse suas experiências místicas. Tais visôes a própria Hildegarda assim descreve, no seu primeiro livro, Scito vias Domini (Conhecer os caminhos do Senhor), que depois foi abreviado simplesmente por Scivias:

E sucedeu no $1141^{\circ}$ ano da encarnação de Jesus Cristo, Filho de Deus, quando eu tinha 42 anos e sete meses de idade, uma ardente luz de um intenso brilho veio do céu para se pôr por completo em minha mente, como uma chama que náo queima mas que ilumina. Ela me preencheu totalmente, coração e alma, como um sol que esquenta algo com seus raios. E mais uma vez eu poderia ter o gosto de entender realmente o que diziam e o que significavam os Sagrados Livros - Os Salmos, os Evangelistas e os

\footnotetext{
${ }^{2}$ Digo a primeira grande experiência mística, porque desde criança Hildegarda tivera várias pequenas visôes, mas foi esta que a levou a escrever e pregar. Segundo relato da própria Hildegarda, contido no segundo volume de sua Vita, iniciada por seu primeiro biógrafo, o monge Gottfried, "[...] ela teve sua primeira experiência visionária ainda antes dos 5 anos de idade. Segundo tal relato, enquanto caminhava com sua ama, a pequena Hildegarda exclamou: 'Veja que bezerrinho bonitinho dentro desta vaca. Ele é branco com manchas no peito, nas patas e nas costas'. Quando o bezerro nasceu, algum tempo depois, constatou-se que era exatamente conforme a descriçāo de Hildegarda" (POLL, 2010. p. 56).
} 
demais livros do Antigo e Novo Testamento [...] (HILDEGARDA DE BINGEN, Scivias, 5).

No final, uma voz lhe ordenou, por três vezes consecutivas: "Oh, mulher frágil, cinza de cinza e corrupção de corrupção, proclama e escreve o que vês e ouves" (HILDEGARDA DE BINGEN, Scivias, 5).

A partir de entáo, isto é, tendo recebido o aval da Igreja, Hildegarda assumiu sua missão como uma verdadeira "profetisa”. Assim, já em 1151, semelhante a Moisés no Exodo, que foi o modelo de profetismo escolhido para seguir desse momento em diante, deixa Disibodenberg e parte na companhia de algumas monjas para Rupertsberg, próximo a Bingen, com a finalidade de revitalizar o antigo mosteiro de Monte Rupert, construído no passado sobre a tumba de São Rupert ${ }^{3}$. Ali, com um carisma e espírito literário, age semelhante aos profetas do Antigo Testamento, em que aparecem os três elementos típicos do profetismo: 1. declaração de sua própria incapacidade; 2. iluminação do alto e 3. graça divina, que a fez superar sua incapacidade, a exemplo de Jeremias, Isaías etc. Daí afirmar Chiara Zamboni que, em diversos momentos de seus escritos, Hildegarda se declara ou se apresenta como uma "pequena mulher" ou "pobre mulherzinha", ou uma mulher humilde que não tem estudos ${ }^{4}$. Ou seja, com a consciência que de "[...] o conhecimento

\footnotetext{
${ }^{3}$ Nesse mosteiro, Hildegarda viveria até o final da vida, conforme veremos mais adiante.

${ }^{4} \mathrm{Um}$ dos pontos controversos da vida de Hidelgarda é quanto a sua capacidade intelectual, uma vez que ela mesma se apresenta como uma mulher humilde ou um "[...] frágil ser humano, ingênua e ignorante" (Scivias, 5), e os principais biógrafos dela dizem que ela não frequentou uma escola regular, senão que sua formação não passou de pequenos conhecimentos adquiridos no mosteiro, sob a instrução de Jutta, por isso, para alguns comentadores, trata-se de uma experiência sobrenatural, na qual ela é apenas um veículo, conforme enfatizam Cirlot e Gari (1999, p. 55): "A palavra de Hildegarda e sua escritura foram possíveis graças a que ela não era nada, senão só receptáculo e transmissão da vontade de Deus. Sua autoridade procedia de que não era ela que falava, senão a voz que ouvia na visão". E é o que vemos em suas próprias palavras, escritas no prólogo de sua primeira obra, Scivias, quando escreve: "E eis que foi no ano de quarenta e três do curso de minha vida temporal, quando em meio a um grande temor, tendo uma celeste visão, vi uma grande claridade em se ouve uma voz que vinha do céu que dizia: 'Frágil ser humano [...] escreve o que vez e ouves. Mas como tens medo de falar, como eis ingênua e ignorante para escrever, fala e escreve náo fundamentada na linguagem dos homens, não na inteligência e na invençáo humana, senão fundamentada no fato de que vez e ouves o que vem de cima, no céu, nas maravilhas de Deus'. E de novo ouvi uma voz que me dizia: 'Proclama estas maravilhas, escreve o que tens aprendido"' (Scivias, 5). Mas, apesar de apresentar-se como tal, alguns "[...] estudiosos de história medieval reconhecem que nos seus escritos há um vasto conhecimento dos textos mais lidos nas Escolas de Teologia e nas Universidades de seu tempo" (ZAMBONI, 1997, p. 26), sinal de que ela não era uma mulher sem estudos, como dizia. É o que reforça Santucci, 2012: "Em suas obras, contrariamente à sua pretensăo de ser ignorante, Ildegarda provou ter um bom
} 
profético não tem a sua origem nela: Hildegarda se percebe como a portadora de um conhecimento. Ela é mensageira de uma verdade. Mas náo é ela que produz esta verdade" (ZAMBONI, 1997, p. 26).

É o que vemos nas palavras da própria Profetisa:

As palavras que digo não provêm de mim, mas eu as vejo em uma suprema visão [...]. Conservo um lugar na memória para as coisas que apreendo na visão $[\ldots]$.

Vejo, escuto e reconheço no mesmo instante e no mesmo instante apreendo. Mas náo entendo aquilo que vejo, porque náo estudei [...]. Assim náo acrescento outras palavras minhas aquilo que escutei na visão e me exprimo num latim não refinado [...].

As palavras que escuto são como uma chama ardente, assemelhandose a nuvens que se movem no ar. E no mesmo céu vejo o brilho, mas não freqüentemente, de uma outra luz, que chamo luz vivente, que não sou capaz de explicar, nem como e nem quando (HILDEGARDA DE BINGEN, Scivias, 5-35).

Portanto, numa época em que a intelectualidade estava reservada aos homens, "[...] foi o sobrenatural que permitiu a Hildegarda sair dos estreitos marcos que, em princípio, havia lhe reservado seu mundo, para situar-se em um primeiro plano da espiritualidade e cultura da época" (CIRLOT; GARI, 1999, p. 51) ${ }^{5}$.

E dentro desse espírito de humildade, escreveu diversas obras, em que descreve suas visóes ou mensagens recebidas de Deus, dentre as quais: Scivias (Conhecer os caminhos do Senhor), primeira de suas teológicas obras, principiada em 1147, após a supracitada autorização do Papa Eugênio III, e concluída em 1151, em que expóem, de forma ordenada, 26 visốes sobre os

conhecimento não só da Bíblia, mas também dos autores latinos, a filosofia neoplatônica e ciências naturais, como em 'et curae causae' uma espécie de manual prática da medicina e da farmacologia, sobre temas médicos, filosóficos e astrológicos, como em 'Physica', sobre as propriedades das plantas, pedras e animais”. O certo é que não era Hildegarda quem escrevia suas obras, mas um copista ou secretário, que anotava os relatos de suas visōes. O primeiro deles foi Volmar, que, ao falecer, em 1173, foi substituído por Gottfried, que iniciou sua primeira biografia, mas três anos depois faleceu, em 1176, ficando em seu lugar Guibert de Gembloux, que continuou a referida biografia. Por tudo isso, todos concordam que nas suas obras, ou para produzir suas obras, o mais importante são as visôes e não o conhecimento adquirido pelos estudos.

${ }^{5} \mathrm{E}$, mais adiante, completa: "A palavra de Hildegarda e sua escrita foram possíveis graças ao fato de que ela não era nada, senão só receptáculo e transmissão da vontade de Deus. Sua autoridade procedia de que não era ela quem falava, senão a voz que via na visão" (CIRLOT; GARI, 1999, p. 55). 
mistérios da salvação, divididos em três livros: o primeiro (seis visôes) sobre a criação e entrada do mal no mundo, a aurora pela queda de Lúcifer; o segundo (sete visōes), sobre a salvação e a encarnação de Jesus Cristo; e o terceiro (treze visôes), sobre a virtudes de sua tarefa na construção da salvação. Pela estrutura da obra, pode-se perceber que o objetivo principal da autora é, “[...] através dos ensinamentos da doutrina cristã, mostrar o caminho que, por meio da prática das virtudes, deve ser percorrido para se alcançar o reino celeste" (POLL, 2010, p. 82).

Nos anos seguintes, Hildegarda escreveu mais duas obras: o Liber vitae meritorum (Livro dos méritos da vida - 1158-1163), um tratado de ética, que estabelece a oposição entre vícios e virtudes a partir de figuras metafóricas, onde, por exemplo, os vícios são descritos ou retratados em formas grotescas que misturam partes humanas e animais, com o objetivo de mostrar e alertar para o perigo de não encontrar o caminho a ser seguido para alcançar o reino celeste, já apontado no Scivias, por isso é considerado um complemento ou aprofundamento deste.

E o Liber divinorum operorum (Livro das divinas obras - 1163-1174), inspirado no Evangelho de São João, por isso centrado no tema da Caridade ou Amor Divino (representado na figura simbólica de uma mulher linda e forte), em que trata de temas como a Trindade, a Criação e a Redenção, fazendo uma estreita relação entre o homem e o universo, conforme veremos mais adiante. Nessa obra, Hildegarda traça sua antropologia filosófica, em que, além da verdade revelada de que o homem foi criado à imagem de Deus, trabalha a questáo da igualdade/diferença entre o homem e a mulher, a qual veremos na sequência.

Em síntese,

[...] o Livro das divinas obras é inspirado pela visão de uma enorme figura divina, a Caritas ou Amor Divino, e apresenta as ideias mais maduras de Hildegarda sobre cosmologia, história da salvaçáo e escatologia, conduzindo o leitor para um final apocalíptico. Há, na obra, uma meditação reverente sobre o cosmo e suas proporçóes, os quais tem seus análogos microcosmo do corpo humano. Assim a forma humana está inscrita no centro do universo, Cristo, ou o encarnado, está inscrito no centro do tempo. (POLL, 2010, p. 85). 
Ademais, no Liber divinorum operorum (Livro das divinas obras), há uma série de pinturas da própria Hildegarda, que aparecem não só como ilustração (iluminuras), mas como meio pedagógico de transmissão dos conteúdos.

Além disso, escreveu diversas Epistolas (cerca de 400, entre 1147-1179), dirigidas a papas, cardeais, bispos, abades, reis, imperadores, monges e monjas, homens e mulheres de todas as classes, tanto da Alemanha como de outros países, os quais tinham grande admiração e respeito para com seus conselhos, conforme assevera Azucena Adelina Fraboschi, em Prólogo à tradução de uma das Epistolas de Hildegarda ao Papa Anastácio IV:

A obra da abadessa de Bingen leva a inconfundível marca do modo feminino de pensar, de escrever, de atuar, de viver. Em uma palavra, de ser. E ainda assim logrou em seu tempo a aceitaçáo, o respeito e a veneração de Papas, Reis, nobreza, hierarquia eclesiástica e religiosa, intelectuais, médicos, povo, etc. Aceitaram sua ciência, respeitaram sua presença, veneraram suas virtudes. (FRABOSCHI, 2004, p. 13).

Entre os anos de 1151-1158, escreveu uma grande obra de medicina, Liber subtilitatum diversarum naturarum creaturarum (Livro das sutilezas das várias naturezas da criação), que, após sua morte, foi dividido em duas partes: Physica ou Liber simplicis medicanae (Física ou Livro de medicina simples), que é um tratado de medicina naturalista, em nove livros, e Causae et curae ou Liber compositae medicanae (Causas e curas ou Livro da medicina composta). Estas duas últimas obras tratam das causas das enfermidades, seus remédios e o funcionamento interno do corpo humano e sua relação com o cosmo, dentro de uma visão terapêutica de totalidade holística entre os quatro elementos formadores do universo: terra, água, ar e fogo ${ }^{6}$.

\footnotetext{
${ }^{6}$ Segundo Debra (apud HILDEGARDA DE BINGEN, 2012), “[...] não se sabe como ela veio a adquirir seu conhecimento; sua atividade como médica foi toda informal e sua formação nesse campo aconteceu provavelmente de forma autodidata, mas ela pode ter recebido uma base terapêutica prática com Jutta e os monges de Disibodenberg durante seu noviciado. Pois, fazia parte das obrigaçóes das superioras conventuais velar pela saúde de suas monjas, mas a prática profissional do ofício exigia formaçấo universitária, o que era vedado às mulheres. Seja como for, pelo conteúdo do tratado se infere que ela estava familiarizada com a medicina de Galeno, de Hipócrates, as práticas árabes e o curandeirismo tradicional alemão, e deve ter ampliado seus conhecimentos com a prática de atendimento a doentes no seu mosteiro. Também deve ter conhecido as obras de naturalistas antigos como Plínio, o Velho, e Isidoro de Sevilha, bem como os bestiários e livros de maravilhas de sua época, e as teorias dos temperamentos, dos fluidos corporais e dos humores, estabelecidas desde a Antiguidade, mas fez muitas observaçôes originais e inventou diversas terapias novas. $\mathrm{O}$ texto traça um panorama abrangente das práticas medicinais disponíveis em sua época, derivadas das tradiçôes pagãs greco-romanas, muçulmanas, cristãs e folclóricas, e fica clara sua concepção de que a natureza
} 
Aqui, mantendo-se em seu holismo, em que faz uma íntima relação entre corpo e alma, o homem e a natureza, o natural e o sobrenatural, Hildegarda defende que boa parte das doenças dos homens é consequência do pecado original, da perda da harmonia e da integração entre Criador e criatura, recusando-se a ver a doença como um assunto exclusivamente de ordem física, fazendo constantes conexóes entre os males que afligiam a alma e aqueles de que padecia o corpo.

Para alguns comentadores, essa "visão religiosa" das doenças e suas curas é fruto da formação prática que Hildegarda recebeu no mosteiro:

Numa época em que os hospitais ainda eram raros, os mosteiros representavam uma das poucas possibilidades de obter cuidados médicos, embora prevaleça a compreensão de que a medicina dos mosteiros 'considerava a doença um castigo [...] e exigia, portanto, oraçóes e arrependimento, a par de cuidados médicos'. É possível que esta interpretação do caráter eminentemente religioso da medicina nos mosteiros tenha influenciado a apreciação do trabalho médico de Hildegard von Bingen como fruto da sua religiosidade. (ALMEIDA, 2009).

Inclusive, é por esse motivo que certos setores da literatura médica atual não considerem ou não incluem as obras de Hildegarda em seus livros, conforme observa Cybele Almeida (2009):

[...] de fato, uma pesquisa preliminar demonstra esta resistência no fato que Hildegard náo ser mencionada no verbete Medicina do Dicionário de Idade Média organizado por LOYN. O verbete MEDIZIN, do Sachwörterbuch der Mediävistik (DINZELBACHER, 1992, p. 515) menciona apenas o seu nome e datas de nascimento e morte, sem aludir a nenhuma de suas obras. Além disso, obras especializadas em história da medicina, como MARGOTTA e LYONS/PETRUCELLI, a ignoram por completo. Isso se deve provavelmente a um erro de interpretação bastante comum que consiste em apresentar o trabalho médico de Hildegard como resultado puro e simples da sua condiçáo de religiosa.

e o homem são espelhos mútuos e integrados”. Essa informação é confirmada por Almeida (2012): "A Regra da Ordem dos monges beneditinos - uma das primeiras do ocidente - além de regular o cotidiano dos monges preocupava-se com a sua saúde e a ocorrência de doenças. $\mathrm{O}$ resultado dessa preocupação foi a organização de um sistema de cuidados médicos nos mosteiros, com enfermarias para os monges (infirmarium), para os ricos e nobres (domus hospitum) e para os pobres e peregrinos (hospitale pauperum), com a reprodução da ordem social existente também fora dos mosteiros. Estes dispunham também de celas para os médicos, os doentes graves, banhos, farmácia e jardim com ervas medicinais [...] É neste contexto que devemos apreciar a medicina na Idade Média, de modo a compreender as múltiplas funçōes dos mosteiros e o seu papel na formação de Hildegard von Bingen”. 
Isso se deve igualmente por se encontrarem elementos da astrologia e da magia, em suas teorias/práticas médicas, conforme acusa Alic:

\begin{abstract}
Ainda que condenasse a astrologia, Hildegard sustentava que os corpos celestes podiam revelar em ocasióes sinais de Deus. A lua, por exemplo, influía na natureza humana e nos assuntos dos homens [...]. Acreditava ainda que a procriação numa fase inapropriada da lua poderia gerar crianças deformadas. (ALIC apud ALMEIDA, 2009).
\end{abstract}

Além disso, Hildegarda escreveu outras obras menores, como duas biografias de santos, estilo literário em moda na época: a Vita S. Disibodi (Vida de Sáo Disibodo - 1170), escrita a pedido do abade Helenger, de Disibodenberg, louvando a vocaçáo precoce de São Disibodo e sua humildade, comparando-o a São João Batista, e a Vita S. Ruperti (Vida de São Ruperto - 1070-73), produzida certamente para celebrar o santo patrono do mosteiro que Hildegarda reconstruiu sobre as ruínas de um edifício anterior, que honrava o local da tumba do santo.

Produziu ainda alguns pequenos trabalhos exegéticos: Explanatio regulae S. Benedicti (Explanaçâo da regra de São Bento - 1053-65); Explanatio symboli S. Athanasii (Explanação do símbolo de Santo Atanásio - 1065); Expositiones Evangeliorum (Exposição do Evangelho), sobre o ano litúrgico; Solutiones XXXVIII quaestionum (Respostas a 38 questóes - 1178), sobre problemas teológicos propostos pelos monges cistercienses de Villers de Brabante.

Hildegarda é autora também de uma Lingua ignota (Lingua desconhecida ou secreta - 1150), formada por um alfabeto ou Litterae ignotae (Letras desconhecidas), que, segundo Jeffrey Schnapp, é “[...] uma lista com pouco mais de mil termos inventados, a grande maioria trazendo ao lado a tradução latina, seguida da tradução alemã" (SCHNAPP, 2007, p. 70), ou seja, uma espécie de dicionário ou vocabulário de palavras alegóricas ou metafóricas usadas por ela em suas obras, para se fazer entender junto ao povo ou para falar de assuntos científicos com palavras populares ${ }^{7}$.

\footnotetext{
${ }^{7}$ Ainda segundo o supracitado comentador, como médica, especialmente das mulheres, Hildegarda usava termos populares em seus escritos sobre medicina, nomeadamente para falar das partes íntimas do corpo humano, o que foi motivo de críticas por partes de muitos, que a acusaram de obscenidade (cf. Ibid. p. 74). Outros sugerem que essa língua tenha servido como um código secreto para comunicação das monjas, quando em presença de estranhos.
} 
Espelhando-se em outras obras similares de seu tempo, mais especificamente nas Etimologias, de Isidoro de Sevilha, e no Hermeneumatica, do Pseudo-Dositheano, na Lingua ignota de Hildegarda, as palavras estão dispostas em grupos hierarquicamente decrescentes, que vão do geral ao particular, isto é, de cima para o centro e do centro para baixo, quer dizer, de Deus até o homem e daí aos demais seres naturais. Cada um desses degraus, por sua vez, obedece a uma disposição hierárquica descendente, como é o caso do homem, por exemplo, que vai do alto da cabeça até o tórax e deste até a sola dos pés.

Além de escritora, médica, mística e artista plástica, Hildegarda de Bingen era, também, grande música, compositora e dramaturga, chegando a compor 77 cançôes litúrgicas (antífonas, responsórios, sequências, hinos, um Kyrie eleison e um Alleluia) para o uso do mosteiro, que estão reunidas na obra Symphonia armonie celestium revelacionum (Sinfonia da harmonia das revelaçôes celestiais - 1140 - 1150), e um auto dramático-musicado, de cunho didático-moral, intitulado Ordo virtutem ${ }^{8}$ ( $A$ ordem das virtudes - 1150 ), que é um conjunto de 14 peças musicais em forma de um pequeno drama sacro musicado, como forma didática de síntese do Scivias (Conhecer os caminhos do Senhor), descrevendo de maneira dramática a origem e destino final do homem, com uma ilustração teatral e musical das beatitudes do Paraíso?.

Segundo Beverly Mayne Kienzle, em linhas gerais, o Ordo virtutem ( $A$ ordem das virtudes)

[...] é uma dramatização musicada da luta de uma alma que caiu em pecado em busca de redenção. Os personagens principais são a Alma, o Demônio e as personificaçôes das várias Virtudes que concorrem para o resgate da alma caída, e o texto tem uma clara função moralizante. Cada

\footnotetext{
${ }^{8}$ Além dessas obras, na Epistola XXIII, dirigida aos prelados de Mainz, escrita por ocasião do interdito a que foi submetido seu mosteiro, Hildegarda desenvolve sua concepção de música. Uma verdadeira teologia musical, a qual está assentada numa visão pitagórica, presente na obra de Regino de Prum, que alude a uma música celestial (o cântico dos anjos no céu), e na classificação boeciana da música (mundana, humana e instrumental). Nesta carta, Hildegarda chega a sustentar que uma das consequências do pecado de Adão foi a "perda da voz", que significa a perda da semelhança com Deus e, portanto, da capacidade de conhecimento. Por isso, apresenta a música como instrumento catequético-pedagógico de recuperação da condiçâao original do homem. A música é colocada no plano revelacional (cf. CIRLOT; GARI, 1999, p. 63).

${ }^{9}$ Os manuscritos das obras de Hildegarda foram reunidos em um arquivo chamado Riesenkodex (livro gigante), "[...] produzido em Rupertsberg logo após a morte de Hildegarda, sob a supervisão do monge Gilbert de Gembloux, que se tornou secretário e amigo da religiosa no final da vida desta. O Riesenkodex preservou todos os textos de caráter proféticos de Hildegarda, incluindo suas correspondências, com exceção de seus textos médico-cientíticos" (POLL, 2010, p. 15). O Riesenkodex encontra-se hoje conservado na Biblioteca Estatal de Hesse, na Alemanha.
} 
Virtude tem pelo menos uma seção solo onde descreve suas características. No final a Alma redimida é levada para o céu, enquanto que as Virtudes, lideradas pela Humildade, acorrentam o Demônio. (KIENZLE apud HILDEGARDA DE BINGEN, 2012).

Em acréscimo, Hildegarda era grande oradora, tendo sido autorizada a proferir Sermóes em público, coisa rara entre as mulheres de seu tempo, conforme informa Carlos Guimarães:

Ela foi uma extraordinária pensadora, uma grande filósofa e teóloga. Ela era uma freira que - coisa raríssima na época - fazia Sermóes públicos, que, além de atrair pela riqueza de conteúdo o povo de sua época, atraia multidóes pelo carisma e pela grande beleza física que possuía, como podemos ver pelas iluminuras que a representam e pelos relatos sobre ela. Dentre outras qualidades, ela era compositora (suas músicas foram recentemente gravadas), escritora, médica, botânica. Era muito dada ao estudo. De certa forma, durante o reinado das trevas, ela possivelmente tenha sido a primeira cientista após a destruição definitiva da Biblioteca de Alexandria. (GUIMARÁES, 2009) ${ }^{10}$.

Mais do que escrever, as visôes de Hildegarda previam uma missão profética evangelizadora, por isso, realizou pelos menos quatro grandes viagens missionárias ao longo dos rios Nahe, Meno, Mosela e Rin (entre 1167 -1171), das quais se destacam: em 1158, foi do Main até Bamberg; em 1160, foi a Tréveris; de 1161 a 1163, viajou pelo Rio Rin, indo até Colônia; de 1170 a 1771, passou por Suabia, indo até Hirsau e Zwiefalten.

Nelas, pregou em diversas igrejas e abadias sobre temas que afetavam a Igreja em seu tempo, principalmente sobre a corrupçáo do clero e o avanço da heresia dos Cátaros. Além disso, em suas viagens, exercia o poder taumaturgo de curar as pessoas de enfermidades diversas.

Por conta de suas pregaçóes, Hildegarda foi muito atacada e hostilizada, durante toda sua vida. Mas, segundo Carlos Guimarães, a pior retaliação aconteceu no final de sua vida,

\footnotetext{
${ }^{10}$ Muitos outros comentadores apresentam Hildegarda como uma mulher para além do seu tempo, como, por exemplo, Cirlot e Gari (1999, p. 49), que enfatizam: "Em pleno século XII Hildegarda de Bingen transpassou as fronteiras do silêncio a que estava submetido seu sexo, para falar e predicar, para escrever acerca de Deus e de sua criaçấo, do homem e do universo". Cf. igualmente CIRLOT (2012, p. 43).
} 
[...] visto que ela, caridosamente, enterrou, em seu mosteiro um jovem revolucionário que havia sido excomungado, quebrando assim uma das mais rígidas leis eclesiásticas da Igreja. Os Bispos exigiram que ela exumasse o corpo, considerado indigno de repousar em terra santa. Ela recusou-se. Dizendo que o jovem morrera em graça e em comunhão com Deus. Seu mosteiro foi imediatamente interditado e ela e suas irmás foram proibidas de participarem da missa. (GUIMARÁES, 2009). ${ }^{11}$

Somente alguns meses antes de sua morte é que seus direitos foram restaurados.

\section{SEU PENSAMENTo}

Como médica, herdeira da tradição médica de Galeno, Hildegarda de Bingen fazia uma estreita correspondência entre o ser humano e o cosmo. Para tanto, dizia que,

[...] assim como o ano é dividido em quatro estaçóes. Como o dia é dividido em quatro partes. Quatro são os temperamentos dos seres humanos: aquele melancólico, aquele colérico, aquele sanguinário e o paciente. Quatro são, também, os elementos do corpo humano: a bile negra, a biles, o sangue e a flegma. Um certo caráter está ligado a uma determinada parte do dia e estaçáo do ano, como está determinado por um certo elemento do corpo. (ZAMBONI, 1997, p. 23).

A idea de complementariedade entre homem e natureza era, para Hildegarda, indispensável. E essa relação de intimidade entre homem e natureza era tal que, segundo o que escreveu, o comportamento humano era capaz de alterar o meio ambiente e vice-versa, atribuindo a irregularidade do clima ao estado de incessante inquietude humana, pois essa agitação confundia os elementos (os quatro elementos: terra, água, ar e fogo) e os fazia saírem de seus limites, com resultados desastrosos, antecipando uma sombria prefiguração dos problemas ecológicos de hoje $\mathrm{e}^{12}$. É o que vemos, por exemplo, no Liber divinorum

\footnotetext{
${ }^{11}$ Poll (2010, p. 90) acrescenta a informação de que o "[...] interdito, a excomunhão coletiva, postulava que, enquanto durasse, as freiras não poderiam nem receber a Comunhão e nem cantar o Ofício Divino, podendo apenas recitá-lo".

${ }^{12}$ A esse respeito, escreve Duran (apud HILDEGARDA DE BINGEN, 2012): "O dado mais original em seu pensamento foi sua forte tendência a analisar tudo numa perspectiva holística, e disso deriva o seu grande apelo para os movimentos ecológicos, pacifistas e naturistas modernos. Ao interligar
} 
operum (Livro das obras divinas), quando, tomando as dores dos elementos da naturais, os faz clamarem por justiça divina contra a insensatez humana:

Todos os elementos e todas as criaturas choram em alta voz diante da profanação da natureza e da devoção maligna da humanidade ao seu modo de vida de rebeliáo contra Deus, enquanto que a natureza irracional cumpre submissa as leis divinas. Eis o motivo pelo qual a natureza protesta táo amargamente contra a humanidade. (HILDEGARDA DE BINGEN, 2012).

Ao que responde Deus:

Eu os purgarei com minhas varas e os atormentarei até que voltem para mim... os ventos terão fedor de putrefação e o ar vomitará tanta sujeira que as pessoas náo ousarão sequer abrir suas bocas. (HILDEGARDA DE BINGEN, 2012).

O Liber divinorum operum (Livro das divinas obras) é um vasto painel de toda criação, em que faz uma correlação entre a descrição da constituição e forma do ser humano, compreendendo seu corpo físico e sua alma, com vários aspectos do microcosmo e do macrocosmo.

A forma humana é vista, pois, como o modelo divino da Encarnação, de acordo com o conceito básico apresentado no Gênesis, e é louvada como uma manifestação da vitalidade, amor e beleza de Deus. Corpo e alma são concebidos como uma unidade integral, onde as forças da natureza e do espírito interagem em harmonia e servem como um espelho para toda a obra da Criação: "Deus inscreveu toda sua obra na forma humana".

Dentro dessa teoria da integração, Hildegarda acabou por defender uma necessidade de complementaridade entre o homem e a mulher. Assim, embora trate da questão mais especificamente nas obras Liber vitae meritorum (Livro dos méritos da vida) e Liber divinorum operum (Livro das divinas obras), já no Scivias (Conhecer os caminhos do Senhor), fazendo uma analogia com os textos paulinos (Ef. 5), compara o amor esposal de Cristo (esposo) e a Igreja (esposa) com o amor entre um homem e uma mulher. E aqui coloca

várias correntes distintas de pensamento em um corpo conceitual bastante integrado, seu trabalho tem afinidade com o de pensadores contemporâneos que não podem ser encaixados facilmente em uma única escola, como Alan Watts e Fritjof Capra. Para Hildegarda, não fazia sentido analisar um fenômeno específico isoladamente, mas era essencial ter uma visão do todo e dos múltiplos relacionamentos estabelecidos entre suas partes". 
o matrimônio como verdadeiro sacramento de amor, que, numa perspectiva cristológico-eclesiológica, aparece como sinônimo de fidelidade, tanto entre Cristo e a Igreja, como entre um homem e uma mulher. Nesse sentido, contra a seita herética dos Cátaros, define o prazer sexual no matrimônio como algo querido por Deus.

Mas é, sobretudo, nas duas supracitadas obras, em que relaciona o ser humano com o resto do Universo, que sua antropologia é evidenciada. Para tal, fazendo uma leitura filosófico-religiosa, considera o ser humano como um microcosmo dentro da criação, em que deve assumir uma atitude de respeito para com a ordem criada e governada por Deus.

Através dessa lógica, estabelece uma complementaridade biológica e psicológica entre homens e mulheres, com igual dignidade entre ambos. No Liber vitae meritorum (Livro dos méritos da vida), por exemplo, salienta que a perfeiçáo de uma pessoa está precisamente em unir harmonicamente em si as características masculinas e femininas ao mesmo tempo. Por isso, a brandura feminina que leva à debilidade necessita do complemento da força masculina, enquanto a força masculina necessita da mansidão e clemência, para náo degenerar em dureza e crueldade. Ou seja, para Hildegarda de Bingen, "[...] a sabedoria é uma mulher forte" (SARANYANA, 1999, p. 155).

Igualmente ao falar de sexualidade, Hildegarda vê o ato sexual e o prazer como algo positivo, daí, mesmo condenando veementemente a luxúria, defende o relacionamento sexual entre um homem e uma mulher - num sentido lato - como essencial para a própria definição de seus gêneros, pois, conforme assinala Heinrich Schipperges, para Hildegarda,

[h]omem e mulher foram atraídos um para o outro desde um plano espiritual, e se manifestaram na encarnação como seres sexuados [...]. Homem e mulher estavam assim tão interligados que um era o verdadeiro produto do outro. Sem a mulher, o homem náo poderia ser chamado de homem; sem o homem a mulher não poderia ser chamada de mulher. Homem e mulher obviamente haviam sido criados um para o outro. (SCHIPPERGES apud HILDEGARDA DE BINGEN, 2012).

Muito embora quebrando um pouco essa ideia de igualdade, em alguns momentos, ao interpretar o Livro do Gênesis $(2,18-22)$ acerca da criaçáo da mulher, coloca a mulher como mais perfeita ou superior ontologicamente que o homem, visto que, se Eva foi criada ou tirada do homem (da costela), 
esta não veio diretamente da terra, como o homem, mas de uma substância superior à terra, o homem. Daí que, comparando o caráter ou temperamento do homem e da mulher, enfatiza que o homem é mais cruel e violento do que a mulher, dada a sua origem ontológica ${ }^{13}$.

Da mesma maneira, quando fala da concepçáo de uma criança, apresenta uma visão totalmente revolucionária em relação à concepção aceita na época, especialmente àquela aristotélica, que afirmava ser o homem o responsável pela definição dos caracteres de uma criança, sendo a mulher apenas um elemento passivo, "[...] um depósito ou receptáculo onde o homem colocava o esperma”, como sustentava Aristóteles. Para Hildegarda de Bingen, é o calor do útero materno que define ou dá a forma a uma criança, a partir do seu sangue.

Assim, mantendo-se no seu esquema de diferença e complementaridade entre ambos, afirma que o versículo bíblico de que "[...] o homem foi feito à imagem e semelhança de Deus" deve ser entendido em sentido genérico, como o "ser humano", no qual está incluído a mulher, o que significa dizer que também a mulher é imagem de Deus, ou melhor, que nem o homem nem a mulher, separadamente, é imagem de Deus.

Mais do que isso, diferentemente de alguns Padres da Igreja que asseguraram a semelhança do homem com Deus apenas pela alma, Hildegarda de Bingen inclui aí também o corpo e, é evidente, o corpo feminino, conforme acentua J.-I. Saranyana:

Convém assinalar que para Hildegarda de Bingen, a mulher não é só imagem de Deus enquanto alma, senão também enquanto corpo, quer dizer, pela carne $[\ldots]$ tanto do varão como da mulher. (SARANYANA, 1999, p. 155).

Todavia, apesar dessa supervalorização da mulher, deixando transparecer, nas entrelinhas, certo feminismo em seu pensamento, o que levou muitos comentadores atuais a classificá-la como uma "teóloga feminista" - ou a ser reverenciada pelos movimentos feministas do século $\mathrm{XX}$, através, por exemplo, de Bárbara Newman, especialmente em sua obra Sister of wisdom: St. Hildegard' theology of th feminine, de 1997 -, não podemos dizer que de fato

\footnotetext{
${ }^{13}$ Não é por acaso que a maioria das personagens simbólicas das visôes de Hildegarda aparece com formas femininas, como, por exemplo, quando descreve e pinta a Caridade ou Amor Divino, tema central de sua obra Liber divinorum operorum (Livro das obras divinas), como uma bela e forte mulher, o que levou muitos comentadores a fazer dela uma "teóloga feminista", conforme veremos mais adiante.
} 
Hildegarda tivesse tal pretensão, muito menos que buscasse uma emancipação da mulher, haja vista que, em nenhum momento, questiona o papel ou a situação social da mulher na Igreja e na sociedade. Em função disso, ressalta Maria Carmen Poll que, "[...] embora Hildegarda tenha sido, de fato, em muitos aspectos uma mulher à frente do seu tempo, ela nunca reivindicou para si ou para o papel das mulheres de sua época qualquer mudança" (POLL, 2010, p. 28-29): pelo contrário, a esse respeito, em muitos pontos defende posiçốes conservadoras ou tradicionais.

Um dos pontos em que Hildegarda é declaradamente conservadora refere-se à não ordenação sacerdotal de mulheres, na Igreja, entendendo que, na grande interação holística do cosmo, na qual o micro deve estar em sintonia com o macro, "[...] as mulheres estavam designadas a ter filhos e criá-los" (Scivias, II, 6), de forma que o sacerdócio era uma atividade incompatível com a função biológica. Por isso, Hildegarda dava capital importância ao casamento, o que a tornava fiel e querida pela ortodoxia católica, segundo comenta Maria Carmen Poll:

A pronta aceitação de Hildegarda no meio eclesiástico não se deve a um único fator, mas um motivo se destaca: a clara ortodoxia de Hildegarda. Não há dúvida que os prelados se sentiram em grande parte atraídos por essa ortodoxia: no Scivias, Hildegarda enfatiza doutrinas como a origem divina do casamento, a santidade da eucaristia e a dignidade do sacerdócio, que os Cátaros negavam veementemente. (POLL, 2010, p. 66).

Em acréscimo, apesar de bater forte no clero da época, em suas cartas e sermões, Hildegarda nunca questionou a Igreja em si, não tentou inaugurar uma nova corrente de pensamento religioso, dentro ou fora da Igreja; sempre permaneceu fiel à ortodoxia da Igreja Católica. Pelo contrário, nesse ponto, foi até considerada conservadora ou tradicional. Por exemplo, quanto à famosa polêmica acerca da estrutura hierárquica e da riqueza na Igreja, mas não só na Igreja, mas em relação às diferenças socioeconômicas na sociedade como um todo, se posicionou contra aqueles que defendiam a chamada "pobreza evangélica”, como, por exemplo, os franciscanos espirituais. Para ela, até entre os anjos há uma hierarquia, daí sua famosa iluminura "As Hierarquias Angélicas", contida no Scivias (Conhecer os caminhos do Senhor).

Também permitiu entre suas monjas o uso de vestes e ornamentos luxuosos, defendendo que, se as mulheres devem se apresentar bem vestidas para seus esposos, quanto mais a Igreja, que é esposa de um rei - Cristo. Por isso, 
[...] em dias de festa, Hildegarda elaborava um ritual em que suas irmãs iam para a igreja rezando os Salmos e tiaras de ouro com um emblema do cordeiro de Deus, anéis de ouro nos seus dedos, e véus de seda branca que chegavam ao chão, sob os quais os cabelos estavam soltos. (POLL, 2010, p. 75).

O uso da tiara de ouro, do véu branco e dos cabelos soltos, por parte das monjas de Hildegarda, foi motivo de severas críticas por setores da Igreja, como por parte do monge Guibert de Gembloux, que questionou o uso da tiara de ouro, o que levou Hildegarda, em carta, a remeter a uma de suas visóes:

Vi que todos os níveis da Igreja têm emblemas brilhantes de acordo com o brilho celestial; mas a virgindade não tem emblema brilhante - nada além de um véu negro e uma imagem na cruz. Entáo eu vi que esse seria o emblema da virgindade: que a cabeça da virgem seria coberta com um véu branco, por causa da vestimenta branca radiante que os seres humanos tinham no paraíso, e perderam. Na cabeça dela [da virgem], havia uma tiara de três cores que se congregariam em uma cor. Porque essa tiara simboliza a Trindade sagrada. (HILDEGARDA, Carta 130 apud POLL, 2010, p. 760).

Já para o uso dos cabelos soltos, Hildegarda justificava que estes eram símbolo da virgindade, daí as monjas deveriam mostrá-los quando iam como noivas ao encontro do seu Esposo - Cristo.

Mais do que isso, Hildegarda se posicionou politicamente a favor dos movimentos hierocratas que, baseados no princípcio agostinianao de que o espiritual é superior ao temporal, defendiam a subordinação do poder temporal ao espiritual, que na prática resultava na defesa da pletinude do poder papal. Nisso, ela foi considerada uma mulher conservadora.

E, mesmo quando de suas admoestaçôes às autoridades eclesiásticas e civis da época, nunca questionou o poder em si, apenas chamava a atenção para que cumprissem suas obrigaçóes, como, por exemplo, sua carta ao Impedador Frederico Barba Roxa:

Sê vigilante, porque no momento todos os reinos da região estáo domidados por reis falciosos que destroem a justiça [...]. Saiba, pois, que o Rei supremo te olha: e não sejais acusado diante d'Ele de não ter exercido corretamente teu ofício e não venhas assim a envergonhar-te [...]. Tome cuidado para que o Supremo Rei não te lance por terra por culpa da cegueira dos teus olhos. Sejai tal, que a graça de Deus não te falte. (HILDEGARDA DE BINGEN apud SOCIEDADE..., 2012). 
Ou quando escreve ao Papa Anastácio IV, admoestando-o acerca do males morais cometidos pelo clero da época:

Por que náo cortaz a raiz do mal que sufoca a erva boa? Por que negligenciais a justiça que vos foi confiada? Como permitais que esta filho do Rei [a Igreja] seja jogada por terra e que seus diademas e ornamentos de sua túnica sejam drestruidos pela grosserei dos homens? Vós que pareceis ter sido cosntituído pastor, levantai-vos e correi em direção á justiça de modo que, diante do Médico supremo, não sejais acusado de nâo ter purificado os teus campos das imundices. Vós homem, mantende-vos no bom caminho e sereis salvo! (HILDEGARDA DE BINGEN apud SOCIEDADE..., 2012)

Ou ainda em sermão, pregando aos clérigos, na Catedral de Trier, em Colônia: "Vejo que sois constituídos como o sol que deve brilhar para os homens pelo fogo da verdadeira doutrina e pelo brilho de uma boa reputação. Vós deveis ser luz, mas sois noite. Escolhei de que lado quereis ficar!" (HILDEGARDA DE BINGEN apud SOCIEDADE..., 2012)

Em síntese, em assuntos políticos e eclesiológicos, o que Hildegarda fez foi combater os males civis, as heresias dentro do seio da Igreja, nomeadamente os Cátaros, a que chama de "lobos em pele de ovelha", e a corrupçáo moral do clero. Portanto, longe de ser uma "reformista", precursora da "reforma protestante", como querem alguns.

\section{IMPORTÂNCIA E ATUALIDADE DE SEU PENSAMENTO}

Hildegarda faleceu em 17 de setembro de 1179, aos 80 anos de idade, no mosteiro de Monte Rupert (Ruperstberg - próximo de Bingen), onde viveu desde 1151, quando deixou Disibodenberg. No momento de seu falecimento, segundo a Vita Sanctae Hildegardis (Vida de Santa Hildegarda) ${ }^{14}$,

[...] sobre a habitação em que a santa virgem entregou sua feliz alma a

Deus no primeiro crepúsculo da noite do domingo, apareceram no céu

\footnotetext{
${ }^{14}$ A Vita Sanctae Hildegardis (Vida de Santa Hildegarda) foi iniciada pelo monge copista Gottfried, que, em fins de 1174 ou no início de 1175, substituíu o antigo copista e confessor Volmar, que havia falecido em 1173. Mas este faleceu em 1176 sem terminá-la. Gottfried foi subsituído por Guibert de Gembloux, que se empenhou em terminar a referida biografia, mas também não completou o trabalho, abordando apenas seus anos iniciais. Somente uma década após a morte de Hildegarda, o monge Theoderic de Echternach retomou o trabalho, acrescentado mais dois volumes e um prefácio (cf. CIRLOT; GARI, 1999, p. 70).
} 
dois arcos brilhantes e de diversas cores, que se prolongaram por um logo caminho estendendo-se pela terra em quatro partes, dos quais um foi de Norte a Sul e outro de Leste a Oeste. No vértice, ali onde os arcos se cruzavam, surgiu uma clara luz em forma de círculo lunar que parecia apartar as trevas da noite de sua habitaçáo [...] o que deve-se crer com quanta claridade havia iluminado a sua amada nos céus. Tampouco faltaram, antes que fora sepultada, milagres que atestam o mérito de sua santidade. Pois dois homens, que cheios de fé tocaram em seu santo corpo. Foram curados de uma grave enfermidade [...]. Seu corpo foi sepultado em lugar santo [...] de onde exala um maravilhoso odor de suavidade, doçura e fragrância saem de seu sepulcro e inunda os sentidos dos homens. (Vita Sanctae Hildegardis, III, XXVII apud CIRLOT; GARI, 1999, p. 70-71).

Além, disso, cultiva-se na memória popular a história de que “[...] seu espírito, rejuvenescido, foi visto várias vezes andando e cantando pela capela, com uma expressão de doce júbilo no rosto. Ela cantava a sua mais conhecida canção: 'O virgia ac diadema”' (GUIMARÃES, 2009).

Hildergada foi sepultada na igreja do mosteiro de Monte Rupert (Rupertsberg - próximo a Bingen). Suas relíquias permaneceram ali até 1632, quando o mosteiro foi destruído pelos suecos. Atualmente, seus restos mortais encontram-se em uma urna, num dos mosteiros fundados por ela, em Eibingen - Alemanha.

\section{Segundo Andréa Frazão, Hildegarda}

[...] não foi oficialmente canonizada pela Igreja, a despeito dos diversos processos que foram instituídos, mas foi considerada santa pela populaçáo desde a Idade Média. Diversos milagres foram-lhe atribuídos ainda em vida e registrados por seus hagiógrafos. Seu nome figura no martirológio romano e sua festa é celebrada em diversas dioceses da atual Alemanha. (SILVA, 2011) ${ }^{15}$.

Complementado as supracitadas palavras, a Enciclopédia Virtual Wikipédia traz as seguintes informaçóes:

Hildegarda nunca foi canonizada oficialmente pela Igreja Católica. Uma tentativa nesse sentido foi orquestrada logo após sua morte por seus amigos e suas monjas, que incluiu o incentivo a romarias à sua tumba, a compilação de uma lista de seus milagres, a construçáo de um altar para ela,

\footnotetext{
${ }^{15}$ Informação confirmada por Cirlot e Gari, 1999, p. 75.
} 
a confecção de versóes de luxo de seus escritos - a origem dos manuscritos iluminados e do Riesencodex que chegaram à contemporaneidade - e, é claro, um pedido formal ao papa Gregório IX, que deu início ao processo regulamentar em 1227, continuado por seus sucessores. Depois de várias delongas, somente em torno de 1233 a comissão encarregada foi ouvir as testemunhas e os recipientes de seus milagres, mas nesta altura muitos já haviam morrido, as curas milagrosas póstumas haviam cessado e sua popularidade já declinara bastante. $\mathrm{O}$ resultado foi o de se abandonar o processo por ausência de evidências suficientes, mas conseguiu-se sua beatificação oficial. Ao longo do século XIII se desenvolveu um culto popular dirigido a ela, em 1324 o papa João XXII autorizou sua veneração pública, e suas relíquias foram autenticadas no encerramento do século XV. Finalmente seu nome foi inscrito como santa na primeira ediçáo do Martirológio Romano, de 1584, aprovada pelo papa Gregório XIII, e sua inclusão foi ratificada na edição revista de 2001 publicada sob os auspícios do papa João Paulo II, que a descreveu como "uma santa extraordinária, uma luz para seu povo e sua época que nos dias de hoje brilha ainda mais intensamente" (HILDEGARDA DE BINGEN, 2012).

\section{Não obstante a Vita Sanctae Hildegardis (Vida de Santa Hildegarda) lhe atribuir}

[...] vinte e cinco curas milagrosas, entre elas a cura de um edema no peito e garganta de uma serva do seu mosteiro ao fazer o sinal da cruz sobre a região afetada; a restauração da visão de um menino com a água do rio Reno, e a cura à distância de um sangramento crônico em uma mulher através do contato de uma carta sua contendo uma bênçáo, e depois de sua morte foram relatadas outras curas de peregrinos junto ao seu túmulo. (HILDEGARDA DE BINGEN, 2012).

Analisando a importância de Hildergada para atualidade, Barbara Newman salienta que

[...] sua contribuição foi tão excepcional em se tratando de uma mulher de sua época, que os pesquisadores modernos, com todo seu aparato teórico e instrumental, ainda consideram difícil analisá-la com suficiente objetividade e avaliar sua real importância. Alguns a consideram simplesmente uma anomalia bem sucedida; muitos compreensivelmente duvidam da origem divina de seus escritos, mas em geral não se dá imprópria a elevadíssima estima que ela desfrutou entre seus contemporâneos, que a chamaram de 'A Sibila do Reno', a 'Profetisa dos Teutóes' e outros epítetos grandiloquentes, nem se vê como injusto ela ter-se tornado um dos ícones do movimento 
feminista do século XX. É de assinalar algumas de suas conquistas: foi a primeira mulher a ser considerada uma autoridade em assuntos teológicos; a única mulher medieval a quem se concedeu o direito de pregar a doutrina cristã em público; a autora do primeiro auto sacro jamais escrito e o único dramaturgo no século XII que não permaneceu anônimo; a única mulher medieval a ser lembrada como compositora de um extenso e qualificado corpo de obras musicais; o primeiro autor a escrever sobre sexualidade e ginecologia de um ponto de vista feminino, e o primeiro santo a ter uma biografia oficial que inclui trechos autobiográficos. (NEWMAN apud HILDEGARDA DE BINGEN, 2012).

Uma prova da importância e reconhecimento da figura de Hildergada, em nossos tempos, são os títulos e monumentos a ela dedicados, como, por exemplo: ela é a patrona do Prêmio Hildegard von Bingen, criado em 1995, na Alemanha, para distinguir jornalistas e publicitários que tenham dado uma contribuição humanitária importante no seu campo e promovido a pluralidade e o diálogo entre homens e mulheres. É nome de uma escola em Rüdesheim Alemanha. É um dos vultos históricos relembrados no Templo de Walhalla, em Regensburg - Alemanha (placa comemorativa no 46). É patrona da Medalha Hildegard von Bingen da Bundesvereinigung Prävention un Gesundheitförderung e.V. para personalidades destacadas no campo da educação sanitária mundial. Sua vida foi objeto de um filme de Margarethe von Trotta, intitulado Vision - Aus dem Leben der Hildegard von Bingen, lançado em 2009. Entre outros exemplos, já existem duas sociedades internacionais dedicadas ao estudo de sua vida e obra, a Internationale Gesellschaft Hildegard von Bingen, fundada na Suíça em 1980, organizando grupos de trabalho, conferências e publicando uma revista, contando com cerca de 1800 membros de vários países do mundo, e a International Society of Hildegard von Bingen Studies, sediada, desde 1983, nos Estados Unidos, também desenvolvendo uma atividade intensa (Cf. HILDEGARDA DE BINGEN, 2012). 
COSTA, Marcos Roberto Nunes. Women intellectuals in the Middle Ages: Hildegard of Bingen - between medicine, philosophy and mysticism. Trans/Form/Ação, Marília, v. 35, p. 187-208, 2012. Edição Especial.

\begin{abstract}
It is common to say that before modernity there is no record of women in the construction of classical thought. What if we take, for example, to philosophy and theology, which were the two areas of knowledge that produced more intellectuals during the Middle Ages, we find there the presence of women. However, despite all the evidence, if we search the construction of Western Thought, we see that it is possible to identify the presence of some women already in ancient times, in Classical Antiquity and Patristics (or Middle Ages). But it is in Scholastic (Middle Ages) we find the first thinkers, responsible for an autonomous system, especially as fertile writers, owners of works so profound and important as those produced by men of his time, who often conversed on an equal footing. In this wonderful universe of female intellectuals, highlight, in Scholastic, the figure of Idelgarda of Bingen (1098-1165), which is discussed a bit in this article.
\end{abstract}

KEYWORDS: Medicine. Philosophy. Mystique. Middle Ages. Women Intellectuals.

\title{
REFERÊNCIAS
}

ALMEIDA, Cybele Crossetti de. Do mosteiro à universidade: consideraçóes sobre uma história da medicina na Idade Média. In: Revista de História - UFRGS. Porto Alegre, v. 2, n. 2, 2009. Disponível em: <http://seer.ufrgs.br/aedos/article/view/9830/5643>. Acesso em: 03 mar. 2012.

CIRLOT, Victoria. Hildegard de Bingen, uma "artista" mística e profética. In: $I H U$ ONLENI - Revista Eletrônica do Instituto Humanitas Unisinos. São Leopoldo, ano XI, edição 385, 2012. Disponível em: <http://www.ihuonline.unisinos.br/media/pdf/ IHUOnlineEdicao385.pdf>. Acesso em: 16 mar. 2012.

CIRLOT, Victoria ; GARI, Blanca. La mirada interior: escritoras misticas y visionárias en la Idade Média. Barcelona: Martinéz Roca, 1999.

FRABOSCHI, Azucena Adelina. Prólogo. In: Carta de Hildegarda de Bingen al Papa Anastasio. (Prol. y Trad. de Azucena Adelina Fraboschi). In: Versiones - Revista de Traducciones Filosóficas. Buenos Aires: Centro "Afonso el Sabio", n. 06, p. 13-17, 2004.

GUIMARÃES, Carlos Antônio Fragoso. O misticismo e os grandes místicos. Disponível em: <http://geocities.yahoo.com.br/carlos.guimaraes/misticos.html>. Acesso em 24 fev. 2009.

HILDEGARDA DE BINGEN. Disponível em: http://pt.wikipedia.org/wiki/Hildegarda_ de_Bingen, Acesso em: 02 mar. 2012.

POLL, Maria Carmen Gomes Martiniano de Oliveira van de. A espiritualidade de Hildegarda von Bingen; profecia e ortodoxia. 2010. 211 f. Tese (Doutorado em História Social) Faculdade de Filosofia, Letras e Ciências Humanas - USP, São Paulo, 2010. Disponível em: 
<http://www.teses.usp.br/teses/disponiveis/8/8138/tde-08032010-113221/pt-br.php>. Acesso em: 03 mar. 2012.

SANTUCCI, Francesca. Ildergarda de Bingen. Disponível em: <http://it.wikipedia.org/ wiki/Ildegarda_di_Bingen>. Acesso em: 07 mar. 2012.

SARANYANA, Josep-Ignasi. História de la filosofia medieval. 3. ed. Pamplona: EUNSA, 1999.

SCHNAPP, Jeffrey. Palavras virgens: a língua ignota de Hildegard de Bingen e o desenvolvimento de línguas imaginárias, da antiguidade à modernidade. In: Neoantiqua. (Trad. Alessandra Vanucci e Maria Lúcia Daflon). Rio de Janeiro: Eduerj, 2007. p. 49-89.

SILVA, Andréa Cristina Lopes Frazão da. Hildegarda de Bingen e as sutilezas da natureza de diversas criaturas. In: 4a Jornada Cientifica - UFRJ - 2002. Disponível em: <http://www. ifcs.ufrj.br/ frazao/Bingen.htm>. Acesso em: 26.09.2011.

SOCIEDADE das ciências antigas. Disponível em: http://www.sca.org.br/biografias/ StaHildegarda.pdf. Acesso em: 04 mar. 2012.

ZAMBONI, Chiara. La filosofia donna: percursi di pensiero femminile. Colognola ai Colli: Demetre, 1997. 